\title{
Role of core needle biopsy as a first-line diagnostic tool for thyroid nodules: a retrospective cohort study
}

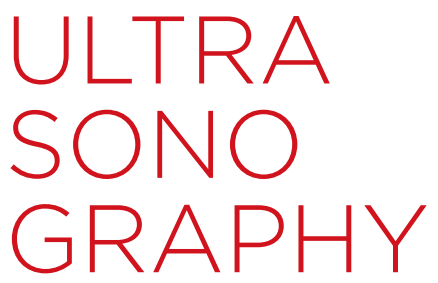

\author{
Min Ji Hong ${ }^{1}$, Dong Gyu Na ${ }^{2,3}$, Soo Jin Kim ${ }^{3,4}$, Dae Sik Kim ${ }^{3,5}$ \\ 'Department of Radiology, Gachon University Gil Medical Center, Incheon; '2Department \\ of Radiology, Gangneung Asan Hospital, Gangneung; ' ${ }^{3}$ Department of Radiology, Human \\ Medical Imaging and Intervention Center, Seoul; ${ }^{4}$ Department of Radiology, New Korea \\ Hospital, Gimpo; ${ }^{5}$ Department of Radiology, Incheon Medical Center, Incheon, Korea
}

\section{ORIGINAL ARTICLE}

https://doi.org/10.14366/usg. 17041 pISSN: 2288-5919 • elSSN: 2288-5943 Ultrasonography 2018;37:244-253
Purpose: The purpose of this study was to evaluate the diagnostic efficacy of fine-needle aspiration (FNA), core needle biopsy (CNB), and combined FNA/CNB for the first-line diagnosis of thyroid nodules.

Methods: A total of 782 consecutive nodules that underwent simultaneous FNA and CNB were analyzed in this study. We compared the rate of inconclusive results and the diagnostic values for malignancy among FNA, CNB, and combined FNA/CNB.

Results: CNB showed a lower rate (10.2\%) of inconclusive results than FNA $(23.7 \%)(P<0.001)$. Combined FNA/CNB showed a lower rate $(6.5 \%)$ of inconclusive results than FNA (all nodules, $\mathrm{P}<0.001$; macronodules, $\mathrm{P}<0.001$; and micronodules, $\mathrm{P}<0.001$, respectively) or CNB (all nodules, $P<0.001$; macronodules, $P<0.001$; and micronodules, $P=0.003$, respectively). Combined FNA/ CNB and CNB showed significantly higher sensitivity, accuracy, and diagnostic performance for malignancy as defined by criterion 1 (Bethesda category $\mathrm{VI}$ ) or criterion 2 (Bethesda categories IV/V/VI) than FNA $(\mathrm{P}<0.001)$. However, there was no significant difference in the sensitivity, accuracy, or diagnostic performance between combined FNA/CNB and CNB (with criterion $1, P=0.063, P=0.063$, and $P=0.412$, respectively; with criterion $2, P=0.500, P=0.500$, and $\mathrm{P}=0.348$, respectively).

Conclusion: CNB was found to be more effective than FNA for the diagnosis of thyroid nodules, and its sensitivity and diagnostic performance for malignancy were similar to those of combined FNA/CNB. CNB has the potential to be an effective alternative first-line diagnostic tool for thyroid nodules when performed by an experienced operator.

Keywords: Thyroid nodule; Thyroid neoplasms; Biopsy, large-core needle; Biopsy, fine-needle; Ultrasonography

\section{Introduction}

Ultrasonography (US)-guided fine-needle aspiration (FNA) has been considered a standard diagnostic
Received: June 7, 2017

Revised: July 26, 2017

Accepted: September 15, 2017

Correspondence to:

Dong Gyu Na, MD, Department of Radiology, Gangneung Asan Hospital, 38 Bangdong-gil, Gangneung 25440, Korea

Tel. +82-33-610-4310

Fax. +82-33-610-3490

E-mail:nndgna@gmail.com

This is an Open Access article distributed under the terms of the Creative Commons Attribution NonCommercial License (http://creativecommons.org/ licenses/by-nc/3.0/) which permits unrestricted noncommercial use, distribution, and reproduction in any medium, provided the original work is properly cited.

Copyright @ 2018 Korean Society of Ultrasound in Medicine (KSUM)

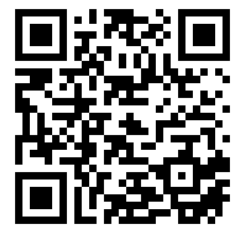

How to cite this article: Hong MJ, Na DG, Kim SJ, Kim DS. Role of core needle biopsy as a first-line diagnostic tool for thyroid nodules: a retrospective cohort study. Ultrasonography. 2018 Jul;37(3):244-253. 
procedure for thyroid nodules [1-3]. However, FNA has limitations and may result in a substantial rate of inconclusive results (usually $6.4 \%-47.3 \%$ of FNA results), including nondiagnostic or atypia of undetermined significance (AUS)/follicular lesion of undetermined significance (FLUS) results [4]. The rate of nondiagnostic FNA results has been reported to be $5 \%-21 \%$ [4-6], while that of AUS/FLUS results is $3 \%-27.2 \%[4,6-9]$. In such a situation, repeat FNA or diagnostic surgery is required for the diagnosis and management of a thyroid nodule $[1,10]$. However, repeated nondiagnostic results occur in $17 \%-47 \%$ of re-aspirated thyroid nodules with previous nondiagnostic samples $[5,7,8,11]$, and the rate of repeated AUS/FLUS diagnoses after repeat FNA has been reported to be up to $67 \%$ [12-15].

Core needle biopsy (CNB) has been proposed as a complementary diagnostic tool to overcome the limitations of FNA. Previous studies [16-20] have reported that simultaneous FNA and CNB was safe and could improve diagnostic adequacy and sensitivity for malignancy in thyroid nodules compared with FNA alone. Based on those studies, we selectively performed simultaneous FNA and CNB, mostly in nodules with US features suspicious for malignancy or follicular neoplasm and when there was a concern about the FNA results being inadequate. Recent studies [21-23] have also reported that combined FNA/CNB showed greater adequacy and diagnostic efficacy than FNA alone. Several studies [24-28] have reported that CNB was more effective for reducing inconclusive results (nondiagnostic or AUS/FLUS) than repeated FNA in nodules with prior nondiagnostic or AUS/FLUS FNA results. Recently, the potential role of CNB as a first-line diagnostic tool in assessing thyroid nodules has been explored [29-31]. However, the role of CNB and combined FNA/CNB as a first-line diagnostic method for thyroid nodules has not been established.

The purpose of this study was to determine whether CNB is more effective than FNA for the first-line diagnosis of thyroid nodules, and we also assessed whether a combined FNA/CNB diagnosis may provide additional diagnostic benefits over FNA or CNB alone.

\section{Materials and Methods}

The Institutional Review Board approved this retrospective study, and the requirement to obtain informed consent was waived.

\section{Study Population}

From February 2010 to December 2014, a total of 1,362 thyroid nodules from 1,219 consecutive patients were subjected to USguided CNB at a single institution. Simultaneous FNA and CNB was performed in 896 nodules from 804 patients, of which 114 nodules from 90 patients were excluded because they had undergone prior FNA or had inconclusive FNA results from other hospitals. A total of 782 thyroid nodules from 714 consecutive patients (588 women, 126 men; mean age, $46.9 \pm 12.9$ years; range, 15 to 86 years) in whom simultaneous FNA and CNB was initially performed were enrolled in this study. The reasons for performing CNB during this period were as follows: (1) nodules with a high risk of nondiagnostic FNA results, such as heavily calcified nodules $(n=50)$ or predominantly cystic nodules $(n=13)$; (2) nodules ( $>5 \mathrm{~mm}$ ) with suspicious US features (at least one of the following US features: a taller-than-wide shape, a spiculated/microlobulated margin, marked hypoechogenicity, microcalcification, and macrocalcification) ( $n=422$ ) [32]; (3) nodules suggestive of a follicular neoplasm (solid nodule with a well-defined smooth margin) ( $n=171)$; (4) candidate nodules for radiofrequency ablation $(n=49)$; and (5) a request from the referring physician $(n=77)$. A final diagnosis of malignancy was based on histopathologic readings from surgical resections or an FNA and/or CNB diagnosis of malignancy. A final diagnosis of a benign nodule was made when one of the following conditions was fulfilled: surgical diagnosis, at least two benign diagnoses on FNA and/or CNB, or one benign diagnosis on CNB or FNA that did not show indeterminate or malignant cytology or histology results on the initial or repeat FNA or CNB.

\section{US-Guided FNA and CNB Procedures}

FNA and CNB procedures were performed under high-resolution color Doppler US guidance using a 10- to $12-\mathrm{MHz}$ linear transducer (AplioXG, Toshiba, Otawarashi, Japan) by an experienced radiologist (D.G.N.) with 15 years of experience in thyroid US imaging and intervention. FNA was performed using the conventional method and at least two samples were obtained from each nodule [33]. CNB was performed using a disposable 18-gauge, single- or double-action spring-activated needle (approximately 1 or $2 \mathrm{~cm}$ excursion; TSK Acecut or Stericut, (reate Medic, Yokohama, Japan), as described previously $[24,34]$. In CNB, the needle notch was positioned to cut some portion of the normal parenchyma (about 2 $\mathrm{mm}$ in length) at the nodule margin, if technically feasible. In most cases, CNB was performed after FNA and the number of CNB biopsies was 1 or 2 . After patients underwent biopsy, we immediately compressed the biopsy site and they were observed during manual self-compression of the biopsy site for 20-30 minutes. We made an effort to obtain satisfactory cytology and histology specimens through a visual assessment of the cytology and histology specimens by the operators during each FNA and CNB procedure.

\section{Cytology and Histology Analyses}

All FNA cytology specimens were interpreted according to the six categories of the Bethesda System for Reporting Thyroid Cytopathology (BSRTC) [10]. The diagnostic categories of CNB for 
thyroid nodules have not yet been standardized. For this study, histologic CNB diagnoses were also categorized into the same six categories of the Bethesda system according to the histopathology results of CNB $[21,24,35]$. Category I (nondiagnostic) included the absence of any identifiable follicular thyroid tissue, the presence of only a normal thyroid gland, and tissue containing only a few follicular cells insufficient for diagnosis. Category III (AUS/FLUS) included nodules with some atypical cells, but not diagnostic of suspected malignancy or malignancy, as well as cellular follicular nodules in which it was not possible to distinguish between a follicular neoplasm and a hypercellular hyperplastic nodule. Category III was subcategorized into nuclear atypia and architectural atypia [35]. Category IV, follicular neoplasm/suspicion for follicular neoplasm (FN/SFN), contained nodules with histological features favoring follicular neoplasm and nodule capsules. Immunohistochemical findings were not taken into account when categorizing the CNB histopathology results.
The combined results of FNA and CNB were also divided into the same six categories to compare the combined results of simultaneous FNA and CNB with those of FNA or CNB alone. The six categories of combined FNA/CNB diagnosis were developed based on the malignancy rate of the combined results of simultaneous FNA and CNB (Tables 1,2) as follows. When both the FNA and CNB results showed nondiagnostic results, the combined FNA/CNB diagnosis was categorized as nondiagnostic. A benign diagnosis was defined as occurring when either the FNA or CNB result was benign and the concurrent FNA or CNB result did not belong to category IV, $\mathrm{V}$, or VI. A diagnosis of AUS/FLUS was made when either the FNA or CNB result belonged to category III and the concurrent FNA or CNB result did not belong to category II, IV, V, or VI. An AUS/FLUS diagnosis was also made when the CNB result was category II and the concurrent FNA result was IV, V, or VI. A FN/SFN diagnosis was made when either the FNA or CNB result was category IV and the concurrent FNA or CNB result did not belong to category V or VI. A

Table 1. Malignancy rate of each combined FNA/CNB result in nodules with a final diagnosis

\begin{tabular}{|c|c|c|c|c|}
\hline \multicolumn{2}{|c|}{ Diagnostic result (category) } & \multicolumn{2}{|c|}{ Final diagnosis $(n=686)$} & \multirow[t]{2}{*}{ Malignancy rate $(\%$} \\
\hline FNA & CNB & Benign $(n=405)$ & Malignancy $(n=281)$ & \\
\hline Nondiagnostic & Benign & 67 & 0 & 0 \\
\hline Nondiagnostic & AUS/FLUS & 1 & 1 & 50 \\
\hline Nondiagnostic & FN/SFN & 1 & 0 & 0 \\
\hline Nondiagnostic & Suspicion of malignancy & 0 & 1 & 100 \\
\hline Nondiagnostic & Malignant & 0 & 5 & 100 \\
\hline Benign & Nondiagnostic & 5 & 0 & 0 \\
\hline Benign & Benign & 318 & 0 & 0 \\
\hline Benign & AUS/FLUS & 4 & 0 & 0 \\
\hline Benign & FN/SFN & 0 & 1 & 100 \\
\hline Benign & Malignant & 0 & 1 & 100 \\
\hline AUS/FLUS & Benign & 2 & 0 & 0 \\
\hline AUS/FLUS & AUS/FLUS & 3 & 4 & 57.1 \\
\hline AUS/FLUS & FN/SFN & 2 & 5 & 71.4 \\
\hline AUS/FLUS & Suspicion of malignancy & 0 & 7 & 100 \\
\hline AUS/FLUS & Malignant & 0 & 17 & 100 \\
\hline FN/SFN & FN/SFN & 2 & 1 & 33.3 \\
\hline Suspicion of malignancy & Suspicion of malignancy & 0 & 4 & 100 \\
\hline Suspicion of malignancy & Malignant & 0 & 59 & 100 \\
\hline Malignant & Benign & 0 & 1 & 100 \\
\hline Malignant & AUS/FLUS & 0 & 1 & 100 \\
\hline Malignant & Suspicion of malignancy & 0 & 4 & 100 \\
\hline Malignant & Malignant & 0 & 169 & 100 \\
\hline
\end{tabular}

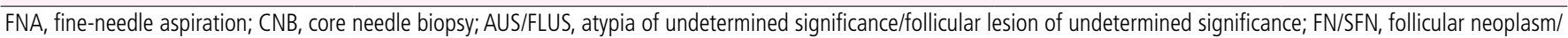
suspicious for a follicular neoplasm.

${ }^{a}$ Diagnoses according to the six categories of the Bethesda system. 
Table 2. Six diagnostic criteria and the malignancy rate of combined FNA/CNB diagnostic results

\begin{tabular}{|c|c|c|c|}
\hline \multicolumn{3}{|c|}{ Diagnostic criteria of combined FNA/CNB diagnosis } & \multirow{2}{*}{ Malignancy rate, $n(\%)^{b)}$} \\
\hline Diagnosis (category) & FNA & CNB & \\
\hline Nondiagnostic (I) & I & I & NA \\
\hline \multirow[t]{2}{*}{ Benign (II) } & $\|$ & I, II, III & 0/396 (0) \\
\hline & I, II, III & $\|$ & \\
\hline \multirow[t]{3}{*}{ AUS/FLUS (III) } & III & I, III & $6 / 10(60)$ \\
\hline & ।, III & III & \\
\hline & $\mid \mathrm{V}, \mathrm{V}, \mathrm{VI}$ & $\|$ & \\
\hline \multirow[t]{2}{*}{ FN/SFN (IV) } & IV & I, III, IV & $7 / 12(58.3)$ \\
\hline & $\mathrm{I}, \mathrm{II}, \mathrm{II}, \mathrm{IV}$ & IV & \\
\hline \multirow[t]{2}{*}{ Suspicious for malignancy (V) } & V & $\mathrm{I}, \mathrm{III}, \mathrm{IV}, \mathrm{V}$ & $12 / 12(100)$ \\
\hline & $\mathrm{I}, \mathrm{II}, \mathrm{III}, \mathrm{IV}, \mathrm{V}$ & V & \\
\hline \multirow[t]{2}{*}{ Malignant (VI) } & VI & $\mathrm{I}, \mathrm{III}, \mathrm{IV}, \mathrm{V}$ & $256 / 256(100)$ \\
\hline & $I, I I, I I I, I V, V, V I$ & $\mathrm{Vl}$ & \\
\hline
\end{tabular}

nodule was considered suspicious for malignancy when either the FNA or CNB result was category V and the concurrent FNA or CNB result was not category $\mathrm{VI}$. A diagnosis of malignancy was made when either the FNA or CNB result was category VI, unless the FNA result was category VI and the CNB result was category II.

\section{Data Analysis and Statistics}

We assessed the rates of inconclusive results (nondiagnostic or AUS/ FLUS) among FNA, CNB, and combined FNA/CNB. The McNemar test was used to compare each diagnostic result of FNA, CNB, and combined $F N A / C N B$, and to compare the diagnostic values of FNA, CNB, and combined FNA/CNB for the diagnosis of thyroid malignancies. The chi-square test or the Fisher exact test was used to compare the malignancy rate within the subcategory of AUS/FLUS on CNB. We compared the diagnostic performance for malignancy among FNA, CNB, and combined FNA/CNB using receiver operating characteristic (ROC) analysis. For the assessment of diagnostic values, we used two criteria of FNA, CNB, and combined FNA/ CNB for the diagnosis of malignancy. Criterion 1 was defined as diagnostic results indicative of malignancy (BSRTC category $\mathrm{VI}$ ) and criterion 2 corresponded to diagnostic results of FN/SFN, suspicious for malignancy, or malignancy (BSRTC category IV/V/VI). Thyroid nodules were also subcategorized according to a size threshold of $1.0 \mathrm{~cm}$. Statistical analysis was performed using SPSS ver. 18.0 for Windows (SPSS Inc., Chicago, IL, USA), and a P-value $<0.05$ was considered to indicate a statistically significant difference.

\section{Results}

\section{Demographic Data}

The mean size (maximum diameter) of the thyroid nodules was $13.8 \pm 10.2 \mathrm{~mm}$ (range, 5 to $70 \mathrm{~mm}$ ). There were 356 micronodules $(<1 \mathrm{~cm})$ and 426 macronodules $(\geq 1 \mathrm{~cm})$. A final diagnosis was made in 686 of the 782 thyroid nodules $(87.7 \%)$. Among these nodules, a final diagnosis of malignancy $(n=281,41.0 \%)$ was made based on histopathologic readings from surgical resections $(n=118)$ or a diagnosis of malignancy (BSRTC category 6) by FNA and/or CNB $(n=163)$. The final diagnoses of the 405 benign nodules $(59.0 \%)$ were determined by (1) a surgical specimen $(n=13) ;(2)$ at least two benign cytology findings on FNA and/or CNB $(n=335)$; or (3) one benign cytology finding on CNB or FNA $(n=57)$.

\section{Diagnostic Results of FNA and CNB}

Discordant results between FNA and CNB were found in 247 of the 782 nodules (31.6\%). CNB showed discordant results in $89.3 \%$ of the category I FNA results, $9.1 \%$ of the category II FNA results, $67.1 \%$ of the category III FNA results, $0 \%$ of the category IV FNA results, $92.5 \%$ of the category $V$ FNA results, and $3.4 \%$ of the category VI FNA results. CNB results of category IV, $\mathrm{V}$, or $\mathrm{VI}$ were found in $45(81.8 \%)$ and a category II CNB result in 10 of the 55 nodules (18.2\%) that showed a category III FNA result and discordant CNB results. A category VI CNB result was found in 59 of the 62 nodules (95.2\%) that showed a category V FNA result and discordant CNB results. 
Among the 782 nodules, 64 (8.2\%) were diagnosed as AUS/FLUS by $\mathrm{CNB}$, including 24 nodules (37.5\%) with nuclear atypia and 40 nodules $(62.5 \%)$ with architectural atypia. In the 14 nodules that received a final diagnosis and had an AUS/FLUS diagnosis by CNB, the malignancy rate was higher in nodules with nuclear atypia than in nodules with architectural atypia (4 of $5,80.0 \%$ vs. 2 of 9 , $22.2 \%)$, but the difference was statistically insignificant $(\mathrm{P}=0.091)$. Among the 52 nodules with AUS/FLUS by CNB and concurrent diagnostic FNA results, the frequency of the CNB subcategory of nuclear atypia was significantly higher in the group of nodules with FNA results of category III, IV, V, or VI than in the group of nodules with FNA results of category II ( 17 of $31,54.8 \%$ vs. 1 of $21,4.8 \%, P=0.001$ ).

\section{Malignancy Rate of Combined FNA/CNB Results}

Tables 1 and 2 show the malignancy rate of each combined FNA/ CNB result in nodules with a final diagnosis. Concordance of the diagnostic results between FNA and CNB was found in 501 of the 686 nodules (73.0\%) with a final diagnosis. In the 501 diagnosed nodules with concordant FNA and CNB results, the malignancy rate of each result category was $0 \%$ for benign, $57.1 \%$ for the category of AUS/FLUS, 33.3\% for the category of FN/SFN, $100 \%$ for the category of suspicion of malignancy, and 100\% for malignant results. In the 81 nodules that received a final diagnosis and had a benign diagnostic result by either FNA or CNB and other concurrent FNA or CNB results, malignant tumors were found in two of the 11 nodules (18.2\%) with a benign FNA diagnosis and other CNB results, and in one of the 70 nodules (1.4\%) with a benign CNB diagnosis and other FNA results (Table 1). In the 81 nodules with a benign diagnosis based on either FNA or CNB, malignant tumors diagnosed by surgery were only found in nodules with concurrent diagnostic results of FN/SFN or malignancy by either FNA or CNB, and there were no malignant tumors in nodules with a concurrent diagnosis of AUS/FLUS by either FNA or CNB. The malignancy rate of each combined FNA/CNB category showed no false negative results within the benign categories and no false positive results in the categories of suggestive of malignancy or malignant. The AUS/FLUS

Table 3. Comparison of diagnostic results among FNA, CNB, and combined FNA/CNB

\begin{tabular}{|c|c|c|c|c|c|c|}
\hline \multirow{2}{*}{ Diagnosis (category) } & \multirow{2}{*}{ FNA } & \multirow{2}{*}{ CNB } & \multirow{2}{*}{ FNA/CNB } & \multicolumn{3}{|c|}{ P-value } \\
\hline & & & & FNA vs. CNB & FNA vs. FNA/CNB & CNB vs. FNA/CNB \\
\hline \multicolumn{7}{|l|}{ All nodules $(n=782)$} \\
\hline Benign (II) & $350(44.8)$ & $396(50.6)$ & $421(53.8)$ & $<0.001$ & $<0.001$ & $<0.001$ \\
\hline AUS/FLUS (III) & $82(10.5)$ & $64(8.2)$ & $40(5.1)$ & 0.076 & $<0.001$ & $<0.001$ \\
\hline Suspicious for malignancy (V) & $67(8.6)$ & $27(3.5)$ & $26(3.3)$ & $<0.001$ & $<0.001$ & $>0.999$ \\
\hline Malignant (VI) & $175(22.4)$ & $251(32.1)$ & $256(32.7)$ & $<0.001$ & $<0.001$ & 0.063 \\
\hline \multicolumn{7}{|l|}{ Nodule size <1 cm ( $\mathrm{n}=356)$} \\
\hline Nondiagnostic (I) & $53(14.9)$ & $7(2.0)$ & $6(1.7)$ & $<0.001$ & $<0.001$ & $>0.999$ \\
\hline Benign (II) & $115(32.3)$ & $141(39.6)$ & $149(41.9)$ & $<0.001$ & $<0.001$ & 0.021 \\
\hline Malignant (VI) & $102(28.7)$ & $155(43.5)$ & $158(44.4)$ & $<0.001$ & $<0.001$ & 0.250 \\
\hline \multicolumn{7}{|l|}{ Nodule size $\geq 1 \mathrm{~cm}(\mathrm{n}=426)$} \\
\hline Nondiagnostic (I) & $50(11.7)$ & $9(2.1)$ & $5(1.2)$ & $<0.001$ & $<0.001$ & 0.125 \\
\hline Benign (II) & $235(55.2)$ & $255(59.9)$ & $272(63.8)$ & 0.017 & $<0.001$ & $<0.001$ \\
\hline AUS/FLUS (III) & $38(8.9)$ & $34(8.0)$ & $20(4.7)$ & 0.652 & $<0.001$ & $<0.001$ \\
\hline FN/SFN (IV) & $5(1.2)$ & $23(5.4)$ & $23(5.4)$ & $<0.001$ & $<0.001$ & $>0.999$ \\
\hline Suspicious for malignancy (V) & $25(5.9)$ & $9(2.1)$ & $8(1.9)$ & 0.004 & 0.001 & $>0.999$ \\
\hline Malignant (VI) & $73(17.1)$ & $96(22.5)$ & $98(23.0)$ & $<0.001$ & $<0.001$ & 0.500 \\
\hline
\end{tabular}

Values are presented as number (\%).

FNA, fine-needle aspiration; CNB, core needle biopsy; AUS/FLUS, atypia of undetermined significance/follicular lesion of undetermined significance; FN/SFN, follicular neoplasm/ suspicious for a follicular neoplasm; NA, not applicable. 
and FN/SFN categories for the combined FNA/CNB diagnosis showed similarly high malignancy rates (60.0\% and $58.3 \%$, respectively).

Comparison of Diagnostic Results among FNA, CNB, and Combined FNA/CNB

The diagnostic results of FNA, CNB, and combined FNA/CNB are shown in Table 3. CNB and combined FNA/CNB showed significantly lower nondiagnostic rates than FNA, regardless of the nodule size $(P<0.001)$. However, there was no significant difference in the nondiagnostic rate between CNB and combined FNA/CNB, regardless of the nodule size (all nodules, $P=0.063$; macronodules, $P=0.125$; and micronodules, $P>0.999$, respectively). Combined FNA/ CNB showed a significantly lower AUS/FLUS rate than FNA or CNB, regardless of the nodule size $(P<0.001)$. However, there was no significant difference in the AUS/FLUS rate between FNA and CNB, regardless of the nodule size (all nodules, $\mathrm{P}=0.076$; macronodules, $\mathrm{P}=0.652$; and micronodules, $\mathrm{P}=0.059$, respectively). In all nodules, CNB and combined FNA/CNB showed significantly higher rates of benign, FN/SFN, and malignant results than FNA $(\mathrm{P}<0.001)$, and significantly lower rates of findings suspicious for malignancy than FNA $(P<0.001)$.

Comparison of Inconclusive Results among FNA, CNB, and Combined FNA/CNB Diagnoses

The inconclusive results of FNA, CNB, and combined FNA/CNB are summarized in Table 4. Inconclusive results were found in 23.7\%, $10.2 \%$, and $6.5 \%$ of overall nodules by FNA, CNB, and combined FNA/CNB, respectively. CNB showed a significantly lower rate of inconclusive results than FNA, regardless of the nodule size $(P<0.001)$. Combined FNA/CNB showed a significantly lower rate of inconclusive results than FNA (all nodules, $\mathrm{P}<0.001$; macronodules, $\mathrm{P}<0.001$; and micronodules, $\mathrm{P}<0.001$, respectively) and CNB (all nodules, $\mathrm{P}<0.001$; macronodules, $\mathrm{P}<0.001$; and micronodules, $P=0.003$, respectively), regardless of the nodule size.

\section{Diagnostic Values of FNA, CNB, and Combined FNA/CNB for Thyroid Malignancy}

Table 5 shows the diagnostic values of FNA, CNB, and combined FNA/CNB in 686 nodules with final diagnoses. The sensitivity and accuracy of combined FNA/CNB and CNB for malignancy were significantly higher than those of FNA using criterion 1 (category $\mathrm{VI}$ ) or criterion 2 (categories IV/V/VI) in all nodules $(\mathrm{P}<0.001$ ), micronodules $(P<0.001)$, and macronodules (combined FNA/CNB vs. FNA, $P<0.001$ for sensitivity with criterion $1, P=0.002$ for sensitivity with criterion $2, P<0.001$ for accuracy with criterion 1 , and $P=0.039$ for accuracy with criterion 2; CNB vs. FNA, $P<0.001$ for sensitivity with criterion $1, P=0.002$ for sensitivity with criterion $2, P<0.001$ for accuracy with criterion 1 , and $\mathrm{P}=0.039$ for accuracy with criterion 2). However, there was no significant difference in sensitivity or accuracy between CNB and combined FNA/CNB for malignancy with criterion 1 or 2, regardless of the nodule size.

In all nodules, combined FNA/CNB and CNB showed significantly better diagnostic performance for the diagnosis of malignancy with criterion 1 or 2 than FNA based on the ROC analysis $(P<0.001)$. The diagnostic performance of combined FNA/CNB and CNB was also better than that of FNA with criterion 1 or 2 in macronodules (FNA/

Table 4. Comparison of inconclusive results among FNA, CNB, and combined FNA/CNB

\begin{tabular}{|c|c|c|c|c|c|c|}
\hline \multirow{2}{*}{ Diagnosis (category) } & \multirow{2}{*}{ FNA } & \multirow{2}{*}{ CNB } & \multirow{2}{*}{ FNA/CNB } & \multicolumn{3}{|c|}{ P-value } \\
\hline & & & & FNA vs. CNB & FNA vs. FNA/CNB & CNB vs. FNA/CNB \\
\hline \multicolumn{7}{|l|}{ All nodules $(n=782)$} \\
\hline AUS/FLUS (III) & $82(10.5)$ & $64(8.2)$ & $40(5.1)$ & 0.076 & $<0.001$ & $<0.001$ \\
\hline Inconclusive (I+III) & $185(23.7)$ & $80(10.2)$ & $51(6.5)$ & $<0.001$ & $<0.001$ & $<0.001$ \\
\hline Nondiagnostic (I) & $53(14.9)$ & $7(2.0)$ & $6(1.7)$ & $<0.001$ & $<0.001$ & $>0.999$ \\
\hline AUS/FLUS (III) & $44(12.4)$ & $30(8.4)$ & $20(5.6)$ & 0.059 & $<0.001$ & 0.006 \\
\hline Inconclusive (I+||I) & $97(27.2)$ & $37(10.4)$ & $26(7.3)$ & $<0.001$ & $<0.001$ & 0.003 \\
\hline \multicolumn{7}{|l|}{ Nodule size $\geq 1 \mathrm{~cm}(\mathrm{n}=426)$} \\
\hline Nondiagnostic (I) & $50(11.7)$ & $9(2.1)$ & $5(1.2)$ & $<0.001$ & $<0.001$ & 0.125 \\
\hline
\end{tabular}

Values are presented as number (\%).

FNA, fine-needle aspiration; CNB, core needle biopsy; AUS/FLUS, atypia of undetermined significance/follicular lesion of undetermined significance. 
Table 5. Diagnostic values of FNA, CNB, and combined FNA/CNB for thyroid malignancy in nodules with a final diagnosis

\begin{tabular}{|c|c|c|c|c|c|c|}
\hline \multirow{2}{*}{ Diagnostic values } & \multicolumn{2}{|c|}{ All $(n=686)$} & \multirow{2}{*}{ FNA/CNB } & \multicolumn{3}{|c|}{ P-value } \\
\hline & FNA & CNB & & FNA vs. CNB & FNA vs. FNA/CNB & 3 CNB vs. FNA/CNB \\
\hline \multicolumn{7}{|l|}{ Criterion 1: category VI } \\
\hline Sensitivity & $175 / 281(62.3)$ & $251 / 281(89.3)$ & 256/281 (91.1) & $<0.001$ & $<0.001$ & 0.063 \\
\hline Specificity & $405 / 405(100)$ & $405 / 405(100)$ & $405 / 405(100)$ & NA & NA & NA \\
\hline PPV & $175 / 175(100)$ & $251 / 251(100)$ & $256 / 256(100)$ & NA & NA & NA \\
\hline NPV & $405 / 511(79.3)$ & 405/435 (93.1) & $405 / 430(94.2)$ & $>0.999$ & $>0.999$ & $>0.999$ \\
\hline Accuracy & $580 / 686(84.5)$ & $656 / 686(95.6)$ & $661 / 686(96.4)$ & $<0.001$ & $<0.001$ & 0.063 \\
\hline \multicolumn{7}{|l|}{ Criterion 2: categories IV, V, VI } \\
\hline Sensitivity & $239 / 281(85.1)$ & $274 / 281(97.5)$ & 275/281 (97.9) & $<0.001$ & $<0.001$ & 0.500 \\
\hline Specificity & 403/405 (99.5) & 400/405 (98.8) & 400/405 (98.8) & 0.250 & 0.250 & $>0.999$ \\
\hline PPV & 239/241 (99.2) & $274 / 279(98.2)$ & $275 / 280(98.2)$ & $>0.999$ & $>0.999$ & $>0.999$ \\
\hline NPV & $403 / 445(90.6)$ & 400/407 (98.3) & $400 / 406(98.5)$ & $>0.999$ & $>0.999$ & $>0.999$ \\
\hline Accuracy & $642 / 686(93.6)$ & $674 / 686(98.3)$ & 676/686 (98.5) & $<0.001$ & $<0.001$ & 0.500 \\
\hline
\end{tabular}

Values are presented as number (\%).

FNA, fine-needle aspiration; CNB, core needle biopsy; NA, not applicable; PPV, positive predictive value; NPV, negative predictive value.

CNB vs. FNA, with criterion $1, P<0.001$, with criterion $2, P=0.006$; CNB vs. FNA, with criterion $1, P<0.001$, with criterion $2, P=0.006$ ) and micronodules $(\mathrm{P}<0.001)$. However, based on the ROC analysis, there was no significant difference in the diagnostic performance between CNB and combined FNA/CNB with criterion 1 (all nodules, $\mathrm{P}=0.412$; macronodules, $\mathrm{P}=0.634$; and micronodules, $\mathrm{P}=0.500$ ) or 2 (all nodule, $\mathrm{P}=0.348$; macronodules, $\mathrm{P}>0.999$; and micronodules, $\mathrm{P}=0.319$ ), regardless of the nodule size. There were no false-positive results using the criterion of category VI. The false-negative rates of FNA, CNB, and combined FNA/CNB were $0.6 \%$ (2 of 329 ), $0.3 \%$ (1 of 388 ), and $0 \%$ (0 of 396$)$, respectively.

\section{Complications}

There were no major complications such as serious hemorrhage in any of the patients, and none required hospital admission or intervention. Four patients $(0.6 \%)$ developed perithyroidal hemorrhage $(n=1)$ or intrathyroidal hemorrhage/edema $(n=3)$ after the procedure. The hematoma and edema resolved following compression for approximately 1 hour. There were no cases of infection or needle track seeding during the follow-up period.

\section{Discussion}

Our study showed that CNB resulted in significantly lower rates of inconclusive results and higher sensitivity, accuracy, and diagnostic performance for malignancy than FNA. Although combined FNA/ CNB showed a lower rate of inconclusive results than FNA or CNB, there were no significant differences in diagnostic performance and sensitivity for malignancy compared with CNB.

Recently, the potential role of CNB as a first-line tool for the diagnosis of thyroid nodules has been investigated. A recent study showed that CNB had low rates of nondiagnostic results $(1.3 \%)$, inconclusive results (5.9\%), and complications (0.2\%), and displayed high diagnostic accuracy (97.6\%) and minimized unnecessary operations (0.5\%) [31]. In another study, the diagnostic accuracy of CNB was significantly higher than that of FNA $(96.8 \%$ vs. $78 \%, P<0.001)$ and reduced the rates of false negative and inconclusive results in nodules with suspicious US features [29]. Our results suggest that CNB could prevent unnecessary repeated biopsy procedures or diagnostic surgery due to inconclusive results in $13.5 \%$ of nodules, and an additional malignant diagnosis (category VI) could be achieved by CNB in $27 \%$ of malignant tumors compared with FNA. When performed by experienced operators, CNB has been reported to be safe $[36,37]$ and tolerable $[38,39]$. Therefore, although FNA has been widely used as a first-line diagnostic tool, CNB may be used by experienced operators as an alternative first-line diagnostic tool for thyroid nodules. However, at present, several limitations of CNB in comparison with FNA hinder its wide clinical application for the diagnosis of thyroid nodules. First, the diagnostic results of CNB may depend on the individual pathologist's experience because standardized pathologic criteria for CNB have not been established. Second, CNB requires operators to have more interventional experience, and less experienced operators may have concerns about potential procedure-related complications. Third, nondiagnostic CNB results due to mistargeting were found only in two of the seven small nodules $(28.6 \%)(<1 \mathrm{~cm})$ that 
showed nondiagnostic CNB results. It should be noted that the risk of mistargeting may increase in small subcentimeter nodules and that CNB may not be technically feasible for small nodules located at the posterior margin of the thyroid.

In our study, the six categories of combined FNA/CNB diagnoses were based on the malignancy rate of the combined results of simultaneous FNA and CNB. Although there were two false-negative cases diagnosed by FNA and one false-negative case diagnosed by CNB (malignant tumors diagnosed as benign nodules by FNA or (NB), these cases were diagnosed as FN/SFN or malignancy based on the combined FNA and CNB diagnosis. This suggests that FNA and CNB play complementary roles in the diagnosis of thyroid nodules, and may explain why there were no malignant tumors in nodules with a combination of benign and AUS/FLUS diagnoses by FNA or CNB. Therefore, nodules with a combination of benign and AUS/FLUS diagnoses were categorized as benign for the combined FNA/CNB diagnosis. Our study suggests that nodules with benign and AUS/FLUS diagnoses by simultaneous FNA and CNB can be considered and managed as benign nodules, considering the very low malignancy rate.

The reasons for discordant FNA and CNB results may be explained primarily by the difference in the volume of the specimen that was obtained and by the different diagnostic criteria of FNA and CNB. First, the large tissue samples obtained in CNB can minimize nondiagnostic results and may reduce AUS/FLUS FNA results related to paucicellular or compromised aspirates [12], and this might explain why we found that the CNB diagnosis was malignant for many nodules diagnosed as suspicious for malignancy by FNA. Second, CNB specimens can provide information about architectural histologic features, including the nodule capsule, as well as information about cellular nuclear features. Although FNA specimens from normofollicular or macrofollicular neoplasms are usually diagnosed as benign, the CNB specimens can be diagnosed as a follicular neoplasm or an indeterminate follicular lesion [35].

Our study showed that combined FNA/CNB slightly reduced the rates of inconclusive results (3.7\% reduction) and false-negative results in rare cases $(0.4 \%)$ compared with CNB alone. However, the diagnostic performance of CNB for malignancy was similar to that of combined FNA/CNB, and the false negative rate of CNB was very low $(<1 \%)$. These data suggest that combined FNA/CNB diagnosis by simultaneous FNA and CNB has a substantial added diagnostic benefit over FNA but has a low added diagnostic benefit over CNB alone for first-line diagnostic use in thyroid nodules. When compared with CNB alone, the routine use of simultaneous FNA and CNB for the first-line diagnosis of thyroid nodules may not be justified over CNB alone due to the low added benefit and procedural burden.

Our study has several limitations. First, there was a patient selection bias based on the retrospective study design. Because CNB was performed mostly in nodules with US features suggestive of malignancy or follicular neoplasm and in nodules with a high rate of nondiagnostic FNA results, our results may not be generalizable to all thyroid nodules. Second, the results of the CNB diagnoses may have been influenced by FNA performed before CNB. Third, the diagnostic categories and histologic criteria of CNB for thyroid nodules have not yet been standardized. Further investigations are required for the standardization of histologic diagnoses based on CNB in thyroid nodules. Fourth, further reproducible studies are required to establish the role of CNB as a first-line diagnostic tool for thyroid nodules because CNB was performed by an experienced radiologist in our study.

In conclusion, CNB was more effective than FNA for reducing inconclusive results and for obtaining accurate diagnoses of malignancy in first-line use for thyroid nodules. Although combined FNA/CNB slightly reduced the rate of inconclusive results, its diagnostic performance for malignancy was similar to that of CNB. Therefore, CNB has the potential to be an effective alternative first-line diagnostic tool in thyroid nodules when performed by experienced operators.

ORCID: Min Ji Hong: http://orcid.org/0000-0001-7818-4346; Dong Gyu Na: http:// orcid.org/0000-0001-6422-1652; Soo Jin Kim: http://orcid.org/0000-0001-82331388; Dae Sik Kim: http://orcid.org/0000-0001-9828-2445

\section{Conflict of Interest}

No potential conflict of interest relevant to this article was reported.

\section{References}

1. Haugen BR, Alexander EK, Bible KC, Doherty GM, Mandel SJ, Nikiforov YE, et al. 2015 American Thyroid Association management guidelines for adult patients with thyroid nodules and differentiated thyroid cancer: The American Thyroid Association Guidelines Task Force on Thyroid Nodules and Differentiated Thyroid Cancer. Thyroid 2016;26:1-133.

2. Gharib H, Papini E, Garber JR, Duick DS, Harrell RM, Hegedus L, et al. American Association of Clinical Endocrinologists, American College of Endocrinology, and Associazione Medici Endocrinologi medical guidelines for clinical practice for the diagnosis and management of thyroid nodules: 2016 Update. Endocr Pract 2016;22:622-639.

3. Shin JH, Baek JH, Chung J, Ha EJ, Kim JH, Lee YH, et al. Ultrasonography diagnosis and imaging-based management of thyroid nodules: revised Korean Society of Thyroid Radiology consensus statement and recommendations. Korean J Radiol 2016;17:370-395. 
4. Bongiovanni M, Spitale A, Faquin WC, Mazzucchelli L, Baloch ZW. The Bethesda System for Reporting Thyroid Cytopathology: a metaanalysis. Acta Cytol 2012;56:333-339.

5. Alexander EK, Heering JP, Benson CB, Frates MC, Doubilet PM, Cibas ES, et al. Assessment of nondiagnostic ultrasound-guided fine needle aspirations of thyroid nodules. I Clin Endocrinol Metab 2002:87:4924-4927.

6. Nayar $R$, Ivanovic $M$. The indeterminate thyroid fine-needle aspiration: experience from an academic center using terminology similar to that proposed in the 2007 National Cancer Institute Thyroid Fine Needle Aspiration State of the Science Conference. Cancer 2009;117:195-202.

7. Yassa L, Cibas ES, Benson CB, Frates MC, Doubilet PM, Gawande $A A$, et al. Long-term assessment of a multidisciplinary approach to thyroid nodule diagnostic evaluation. Cancer 2007;111:508-516.

8. Yang J, Schnadig V, Logrono R, Wasserman PG. Fine-needle aspiration of thyroid nodules: a study of 4703 patients with histologic and clinical correlations. Cancer 2007;111:306-315.

9. Choi YJ, Baek JH, Ha EJ, Lim HK, Lee JH, Kim JK, et al. Differences in risk of malignancy and management recommendations in subcategories of thyroid nodules with atypia of undetermined significance or follicular lesion of undetermined significance: the role of ultrasound-guided core-needle biopsy. Thyroid 2014;24:494501.

10. Cibas ES, Ali SZ. The Bethesda System for Reporting Thyroid Cytopathology. Thyroid 2009;19:1159-1165.

11. Orija IB, Pineyro M, Biscotti C, Reddy SS, Hamrahian AH. Value of repeating a nondiagnostic thyroid fine-needle aspiration biopsy. Endocr Pract 2007;13:735-742.

12. Bongiovanni M, Krane JF, Cibas ES, Faquin WC. The atypical thyroid fine-needle aspiration: past, present, and future. Cancer Cytopathol 2012;120:73-86.

13. Ho AS, Sarti EE, Jain KS, Wang H, Nixon IJ, Shaha AR, et al. Malignancy rate in thyroid nodules classified as Bethesda category III (AUS/FLUS). Thyroid 2014;24:832-839.

14. Hyeon J, Ahn S, Shin JH, Oh YL. The prediction of malignant risk in the category "atypia of undetermined significance/follicular lesion of undetermined significance" of the Bethesda System for Reporting Thyroid Cytopathology using subcategorization and BRAF mutation results. Cancer Cytopathol 2014;122:368-376.

15. Sullivan PS, Hirschowitz SL, Fung PC, Apple SK. The impact of atypia/follicular lesion of undetermined significance and repeat fine-needle aspiration: 5 years before and after implementation of the Bethesda System. Cancer Cytopathol 2014;122:866-872.

16. Liu Q, Castelli M, Gattuso P, Prinz RA. Simultaneous fine-needle aspiration and core-needle biopsy of thyroid nodules. Am Surg 1995;61:628-632.

17. Renshaw AA, Pinnar N. Comparison of thyroid fine-needle aspiration and core needle biopsy. Am J Clin Pathol 2007;128:370-
374.

18. Jordan CD. Equanimity: synchronous fine-needle aspiration cytology and core biopsy of thyroid nodules. Am J Clin Pathol 2007;128:365366.

19. Strauss EB, lovino A, Upender S. Simultaneous fine-needle aspiration and core biopsy of thyroid nodules and other superficial head and neck masses using sonographic guidance. AJR Am J Roentgenol 2008;190:1697-1699.

20. Zhang S, Ivanovic M, Nemcek AA Jr, Defrias DV, Lucas E, Nayar R. Thin core needle biopsy crush preparations in conjunction with fine-needle aspiration for the evaluation of thyroid nodules: a complementary approach. Cancer 2008;114:512-518.

21. Sung JY, Na DG, Kim KS, Yoo H, Lee H, Kim JH, et al. Diagnostic accuracy of fine-needle aspiration versus core-needle biopsy for the diagnosis of thyroid malignancy in a clinical cohort. Eur Radiol 2012;22:1564-1572.

22. Yi KS, Kim JH, Na DG, Seo H, Min HS, Won JK, et al. Usefulness of core needle biopsy for thyroid nodules with macrocalcifications: comparison with fine-needle aspiration. Thyroid 2015;25:657-664.

23. Kiran T, Guler B, Aysan E, Arici DS. Correlation between simultaneous ultrasound-guided fine needle aspiration and core needle biopsy results in thyroid nodules of 44 cases. Diagn Pathol Open 2017;2:123.

24. Na DG, Kim JH, Sung JY, Baek JH, Jung KC, Lee $H$, et al. Coreneedle biopsy is more useful than repeat fine-needle aspiration in thyroid nodules read as nondiagnostic or atypia of undetermined significance by the Bethesda system for reporting thyroid cytopathology. Thyroid 2012;22:468-475.

25. Samir AE, Vij A, Seale MK, Desai G, Halpern E, Faquin WC, et al. Ultrasound-guided percutaneous thyroid nodule core biopsy: clinical utility in patients with prior nondiagnostic fine-needle aspirate. Thyroid 2012;22:461-467.

26. Lee $\mathrm{KH}$, Shin JH, Oh YL, Hahn SY. Atypia of undetermined significance in thyroid fine-needle aspiration cytology: prediction of malignancy by US and comparison of methods for further management. Ann Surg Oncol 2014;21:2326-2331.

27. Pyo JS, Sohn JH, Kang G. Core needle biopsy is a more conclusive follow-up method than repeat fine needle aspiration for thyroid nodules with initially inconclusive results: a systematic review and meta-analysis. J Pathol Transl Med 2016;50:217-224.

28. Cao H, Kao RH, Hsieh MC. Comparison of core-needle biopsy and fine-needle aspiration in screening for thyroid malignancy: a systematic review and meta-analysis. Curr Med Res Opin 2016;32:1291-1301.

29. Trimboli P, Nasrollah N, Guidobaldi L, Taccogna S, Cicciarella Modica DD, Amendola $S$, et al. The use of core needle biopsy as first-line in diagnosis of thyroid nodules reduces false negative and inconclusive data reported by fine-needle aspiration. World I Surg Oncol 2014;12:61. 
30. Zhang M, Zhang Y, Fu S, Lv F, Tang J. Thyroid nodules with suspicious ultrasound findings: the role of ultrasound-guided core needle biopsy. Clin Imaging 2014;38:434-438.

31. Suh CH, Baek JH, Lee JH, Choi YJ, Kim JK, Sung TY, et al. The role of core-needle biopsy as a first-line diagnostic tool for initially detected thyroid nodules. Thyroid 2016;26:395-403.

32. Moon WJ, Baek JH, Jung SL, Kim DW, Kim EK, Kim JY, et al. Ultrasonography and the ultrasound-based management of thyroid nodules: consensus statement and recommendations. Korean J Radiol 2011;12:1-14.

33. Lee YH, Baek JH, Jung SL, Kwak JY, Kim JH, Shin JH, et al. Ultrasoundguided fine needle aspiration of thyroid nodules: a consensus statement by the Korean Society of Thyroid Radiology. Korean J Radiol 2015;16:391-401.

34. Na DG, Baek JH, Jung SL, Kim JH, Sung JY, Kim KS, et al. Core needle biopsy of the thyroid: 2016 consensus statement and recommendations from Korean Society of Thyroid Radiology. Korean J Radiol 2017;18:217-237.
35. Jung CK, Min HS, Park HJ, Song DE, Kim JH, Park SY, et al. Pathology reporting of thyroid core needle biopsy: a proposal of the Korean Endocrine Pathology Thyroid Core Needle Biopsy Study Group. J Pathol Transl Med 2015;49:288-299.

36. Baloch ZW, Cibas ES, Clark DP, Layfield LJ, Ljung BM, Pitman MB, et al. The National Cancer Institute Thyroid fine needle aspiration state of the science conference: a summation. Cytojournal 2008;5:6.

37. Ha EJ, Baek JH, Lee JH, Kim JK, Choi YJ, Sung TY, et al. Complications following US-guided core-needle biopsy for thyroid lesions: a retrospective study of 6,169 consecutive patients with 6,687 thyroid nodules. Eur Radiol 2017;27:1186-1194.

38. Stangierski A, Wolinski K, Martin K, Leitgeber O, Ruchala M. Core needle biopsy of thyroid nodules: evaluation of diagnostic utility and pain experience. Neuro Endocrinol Lett 2013;34:798-801.

39. Nasrollah N, Trimboli P, Rossi F, Amendola S, Guidobaldi L, Ventura C, et al. Patient's comfort with and tolerability of thyroid core needle biopsy. Endocrine 2014;45:79-83. 